\title{
Wisdom Tooth Formation as a Method of Estimating Age in a New Zealand Population
}

\author{
Annabelle McGettigan ${ }^{1}$, Kimberley Timmins ${ }^{1}$, Peter Herbison², Helen Liversidge ${ }^{3}$ and Jules Kieser ${ }^{1 *}$ \\ 'Sir John Walsh Research Institute, Faculty of Dentistry, University of Otago, Dunedin, New Zealand \\ ${ }^{2}$ Department of Preventive and Social Medicine, Dunedin School of Medicine, University of Otago, Dunedin, \\ New Zealand
}

${ }^{3}$ Department of Paediatric Medicine, Queen Mary University of London, London E1 2AD, United Kingdom

\begin{abstract}
Dental ageing relies on assumptions about the progression of tooth development from the middle trimester to adulthood and relative stability of this process in the face of adverse dietary, hormonal, disease or nutritional factors. Most studies of dental ageing employ the method of Demirjian et al., (1973), which is based upon an assessment of crown and root formation stages from dental radiographs. Unfortunately, this method has a ceiling effect at age 16, when the second molar attains full maturity. The aim of our study was to extend the window of ageing by using the development of the third molar teeth. Panoramic radiographs of 207 (105 males) children aged between 7 years, 6 months and 18 years formed the basis of this study. Upper and lower left wisdom teeth were scored according to Demirjian et
\end{abstract}

Tooth formation is a developmental process that is thought to be less influenced by environmental insults than other markers of development and is thus regarded to be an accurate method for estimating chronological age (Demirjian et al., 1985). A substantial body of research by the same author into the timing of development of the dentition has focused on well-described stages applied to large samples (Demirjian et al., 1973; Demirjian and Goldstein, 1976; Demirjian and Levesque, 1980; Demirjian, 1994). Our earlier research into dental ageing of New Zealand populations used Demirjian's method to record standards for dental development in European, Pacific Island and Maori children (Kieser et al.,2008; TeMoananui et al., 2008a, 2008b). More recently, we contrasted the use of Demirjian's method with that of Cameriere and coworkers (2006). While we found that both the methods reliably predicted chronological age in children aged 7-17 years, a disadvantage of using the Cameriere method was that all seven teeth reached maturity at 13.69 and 14.06 years in females and males, respectively, compared to age 16 using Demirjian (Timmins et al., 2011). Because neither method predicted age beyond 16 years, we decided to evaluate the usefulness of the Demirjian method when applied to third molar development in the same population sample. al. (1973) by a single examiner. Intra-examiner reliability was evaluated by repeat scoring of a randomly selected $(10 \%)$ sample one week after the initial staging. These showed a consistency of $76 \%$ for the mandibular data and $95 \%$ for the maxillary data, giving an overall percentage of $85 \%$. When the re-scored teeth were not consistent with their original score, this differed only by one stage. In this population males were advanced in their third molar development and this trend was more marked for maxillary than mandibular wisdom teeth. Hence, the New Zealand population examined, males were more advanced in their third molar development and this trend was more marked for maxillary than mandibular teeth. Dental Anthropology 2011;24(2):33-41.

\section{MATERIALS AND METHODS}

We sourced a total of 207 panoramic radiographs of children aged between 7 years, 6 months and 18 years from various orthodontic clinics throughout New Zealand, described previously (Timmins et al., 2011). Photographic images of the radiographs were captured using a Canon IXUS 870IS 10 mega-pixel camera with a 28 $\mathrm{mm}$ wide-angle lens and optical image stabilizer. The sex distribution of our sample was 105 males to 102 females. There were 20 participants ( 10 male and 10 female) in each age category up to age 17 , but in the category for age 18 there were two females and five males. Some radiographs had to be excluded because the wisdom tooth of interest had been cropped out of the picture, the radiographic quality was too poor to adequately score the tooth, or the wisdom tooth had not yet started to develop and it was deemed to be congenitally missing. If the second molar displays parallel root canal spaces and the apex is half closed (converging root canal apices) or fully closed, then

*Corresponding author: Jules Kieser, Sir John Walsh Research Institute, Faculty of Dentistry, University of Otago, Dunedin 9054 New Zealand

Email: jules.kieser@otago.ac.nz 
it is highly likely the third molar is congenitally missing and will not develop. If the second molar is less mature than this, then it is still possible that the third molar might develop. Armed with this knowledge we were able to exclude those whose wisdom teeth were congenitally missing from our data set. After all exclusions, we were left with 193 radiographs for the lower left wisdom teeth and 180 radiographs for the upper left wisdom teeth, a full breakdown of the age and sex distribution of our final sample can be found in Table 1 .

The upper and lower left wisdom tooth was scored according to a modified version of Demirjian et al. (1973) for staging the formation of the dentition, as illustrated in Figure 1. A single examiner evaluated both the upper and lower left wisdom teeth according to these criteria using a standard zoom facility with contrast enhancement. When we were unable to score the wisdom tooth of interest because the photograph had been cropped, the antimere was scored instead when visible.

We examined intra-examiner reliability by repeating the scoring for a randomly selected $10 \%$ of the sample one week after the initial staging. For statistical analysis of the data set, age for each individual was recorded to two decimal places to allow for more accurate analysis of the correlation between chronological and dental age. The prediction of age from maturity status was done using polynomial regression with linear, quadratic and cubic terms. This required the assumption that the maturity stages are equally spaced.

0 Crypt outline visible, no calcification.

A Calcification seen, no fusion of points.

B Fusion of calcified points.

C Enamel formation complete, crown $1 / 2$ formed,pulp chamber curved.

D Crown formation is complete, pulp chamber is trapezoidal, root formation commenced.

E Radicular bifurcation observed; root length less than crown height.

F Root endings flared; root length at least equal to crown height.

G Root canal walls parallel, apices open.

$\mathrm{H}$ Apex closed, uniform periodontal space.

\section{RESULTS}

Intra-observer validity tests showed a consistency of $76 \%$ for the mandibular data and $95 \%$ for the maxillary data, giving an overall percentage of $85 \%$. When the rescored teeth were not consistent with their original score, this differed only by one stage.

In this population, it appears that males are advanced in their third molar development as can be seen by the mean age of each developmental stage, this is more marked for maxillary wisdom teeth than mandibular wisdom teeth. After age 15, no stage lower than stage "C" was observed for both mandibular and maxillary wisdom teeth and thus it can be hypothesized that in this population the presence of wisdom teeth at stage B or lower is indicative of age $<15$ (Tables 2,3 ). Stage " $F$ " was observed in only one individual below the age of 16, thus if stage " $\mathrm{F}$ " is observed in an individual, it is highly likely that the individual is 16 years or older.

A considerable amount of disagreement existed between the staging of the mandibular wisdom tooth and the staging of the maxillary wisdom tooth and this disagreement was statistically significant (Table 4).

Figures 2 and 3 show actual age of male and female participants as a function of the developmental scores for mandibular and maxillary wisdom teeth respectively. Confidence intervals (95\%) are given by the dotted lines. It is clear that females develop faster than males. Figures 4 and 5 show box-and-whisker plots of Demirjian's dental stages as well and chronological ages for mandibular and maxillary teeth in males and females. Outliers are depicted as small circles. Again, it is evident that boys

TABLE 2. Maxillary staging by chronological year of age

\begin{tabular}{|c|c|c|c|c|c|c|c|c|c|c|c|c|}
\hline Stage & 8 & 9 & 10 & 11 & 12 & 13 & 14 & 15 & 16 & 17 & 18 & Total \\
\hline $\begin{array}{l}\text { Size } \\
\text { size: }\end{array}$ & 15 & 15 & 6 & 4 & 6 & 2 & 1 & - & - & - & - & 49 \\
\hline A & 2 & 1 & 3 & - & - & - & - & - & - & - & - & 6 \\
\hline B & 2 & 4 & 5 & 1 & 4 & 3 & 1 & - & - & - & - & 19 \\
\hline C & - & - & 3 & 6 & 5 & 3 & 6 & 2 & 1 & 2 & - & 28 \\
\hline D & - & - & 1 & 5 & 3 & 10 & 7 & 8 & 6 & 5 & - & 45 \\
\hline E & - & - & - & - & 1 & 1 & 1 & 5 & 6 & 2 & - & 16 \\
\hline $\mathbf{F}$ & - & - & - & - & - & - & - & - & 4 & 4 & 1 & 9 \\
\hline G & - & - & - & - & - & - & - & - & - & 3 & 4 & 7 \\
\hline $\mathbf{H}$ & - & - & - & - & - & - & - & - & - & - & 1 & 1 \\
\hline total & 19 & 20 & 18 & 16 & 19 & 19 & 19 & 18 & 18 & 20 & 7 & 180 \\
\hline
\end{tabular}


Fig. 1. Modified staging method based on Demirjian et al. (1973).

\begin{tabular}{|c|c|}
\hline 0 & $\begin{array}{l}\text { Outline visible, no } \\
\text { calcification. }\end{array}$ \\
\hline A & $\begin{array}{l}\text { Calcification seen, } \\
\text { no fusion of points. }\end{array}$ \\
\hline B & $\begin{array}{l}\text { Fusion of calcified } \\
\text { points. }\end{array}$ \\
\hline$C$ & $\begin{array}{l}\text { Enamel formation } \\
\text { complete, crown } 1 / 2 \\
\text { formed, pulp chamber } \\
\text { curved. }\end{array}$ \\
\hline D & $\begin{array}{l}\text { Crown formation is } \\
\text { complete, pulp chamber } \\
\text { is trapezoidal, root } \\
\text { formation commenced. }\end{array}$ \\
\hline$E$ & $\begin{array}{l}\text { Radicular bifurcation } \\
\text { observed; root length < } \\
\text { crown height. }\end{array}$ \\
\hline $\mathrm{F}$ & $\begin{array}{l}\text { Root endings flared; } \\
\text { root length }>=\text { crown } \\
\text { height. }\end{array}$ \\
\hline G & $\begin{array}{l}\text { Root canal walls } \\
\text { parallel, apices open }\end{array}$ \\
\hline $\mathrm{H}$ & $\begin{array}{l}\text { Apex closed, uniform } \\
\text { periodontal space. }\end{array}$ \\
\hline
\end{tabular}


TABLE 3. Mandibular staging by chronological year of age

\begin{tabular}{crrrrrrrrrrrr}
\hline Stage & $\mathbf{8}$ & $\mathbf{9}$ & $\mathbf{1 0}$ & $\mathbf{1 1}$ & $\mathbf{1 2}$ & $\mathbf{1 3}$ & $\mathbf{1 4}$ & $\mathbf{1 5}$ & $\mathbf{1 6}$ & $\mathbf{1 7}$ & $\mathbf{1 8}$ & Total \\
\hline $\begin{array}{c}\text { Sample } \\
\text { size: }\end{array}$ & 15 & 9 & 6 & 4 & 5 & 1 & 6 & - & - & - & - & 46 \\
O & 1 & 2 & 3 & 2 & 1 & - & - & - & - & - & - & 9 \\
A & 4 & 7 & 1 & 2 & 2 & 1 & 1 & - & - & - & - & 18 \\
B & - & 2 & 7 & 5 & 6 & 1 & - & - & - & - & - & 21 \\
C & - & - & 2 & 5 & 2 & 12 & 5 & 6 & 4 & 1 & 1 & 38 \\
D & - & - & - & 2 & 3 & 5 & 4 & 7 & 5 & 4 & - & 30 \\
E & - & - & - & - & 1 & - & 3 & 5 & 5 & 5 & 3 & 22 \\
F & - & - & - & - & - & - & 1 & - & 1 & 2 & 1 & 5 \\
G & - & - & - & - & - & - & - & - & 1 & 2 & 1 & 4 \\
H & - & - & - & - & - & - & - & - & - & - & - & 0 \\
total & 20 & 20 & 19 & 20 & 20 & 20 & 20 & 18 & 16 & 14 & 6 & 193 \\
\hline
\end{tabular}

develop later than girls.

\section{DISCUSSION}

From these data, New Zealand population-specific prediction charts were developed to aid estimation of chronological age from wisdom tooth stage as shown in Figures 4 and 5. Normal development charts were also generated to aid orthodontic treatment planning to determine whether an individual's development is normal, advanced or delayed (Figs. 2 and 3). It must be noted, however, that these charts assume there is an equal distance between each of the stages; that is, the time difference between A and B is the same as the difference between D and E. It is highly likely that this is not the case, and these stages may in fact be staggered with one lasting only a few months and others maybe lasting a few years. Hägg and Matsson (1985) observed that earlier stages of tooth formation were generally of shorter duration than later stages with regard to teeth 41 through to 47 (FDI scoring system), and this is likely to be the case also with regard to the third molar.

Gunst et al. (2003) set out to calculate the chronological age of Belgian Caucasian individuals based on the development of the third molars using a 10-stage developmental scoring method proposed by Kohler and co-workers (1994). They found a slight sexual dimorphism with relation to timing of the stages (males had a younger mean age for each stage), and a trend for earlier development in maxillary third molars compared to mandibular. Generally, however, the relationship between chronological age and dental age of the third molars has been investigated using variations of Demirjian's stages. In 2004, Arany et al. used Demirjian's stages to estimate the probability of a Japanese adolescent being over the ages of 14, 16 and 20 (the relevant ages as determined by Japanese juvenile law). This study found

TABLE 4. Mandibular versus maxillary staging

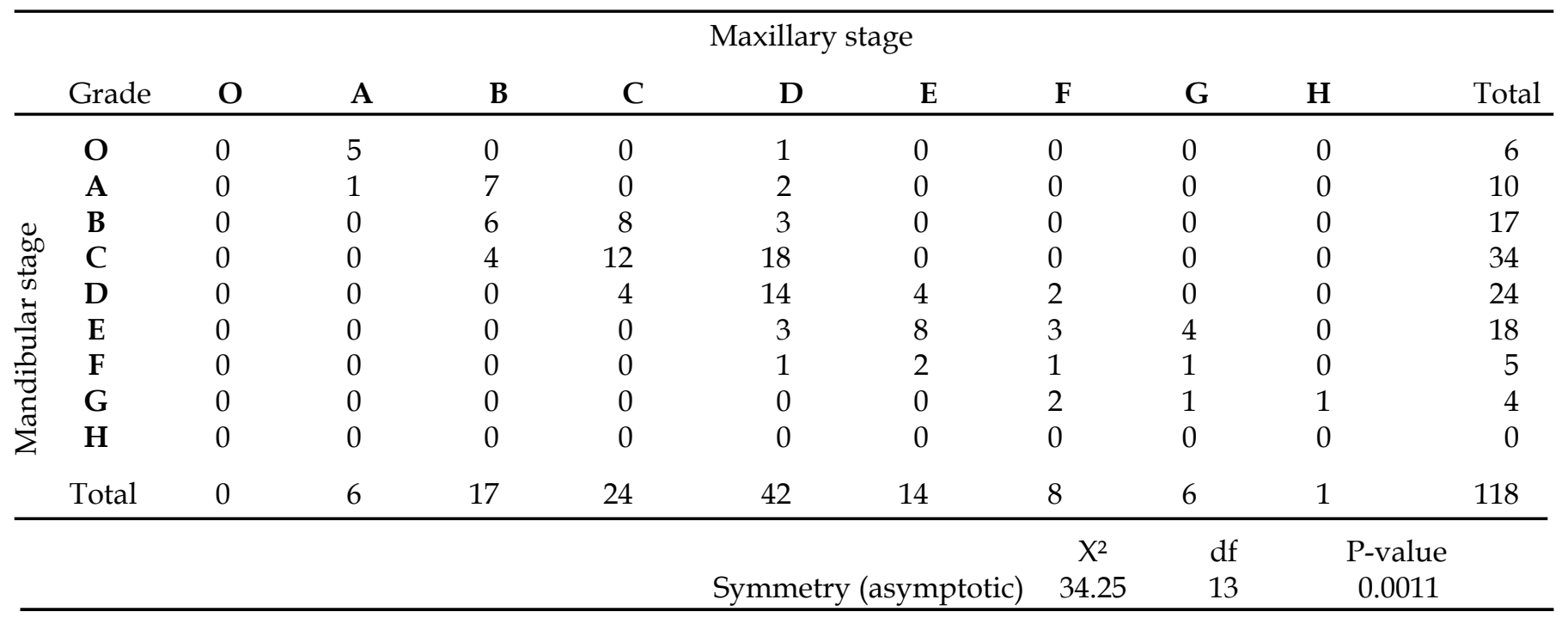




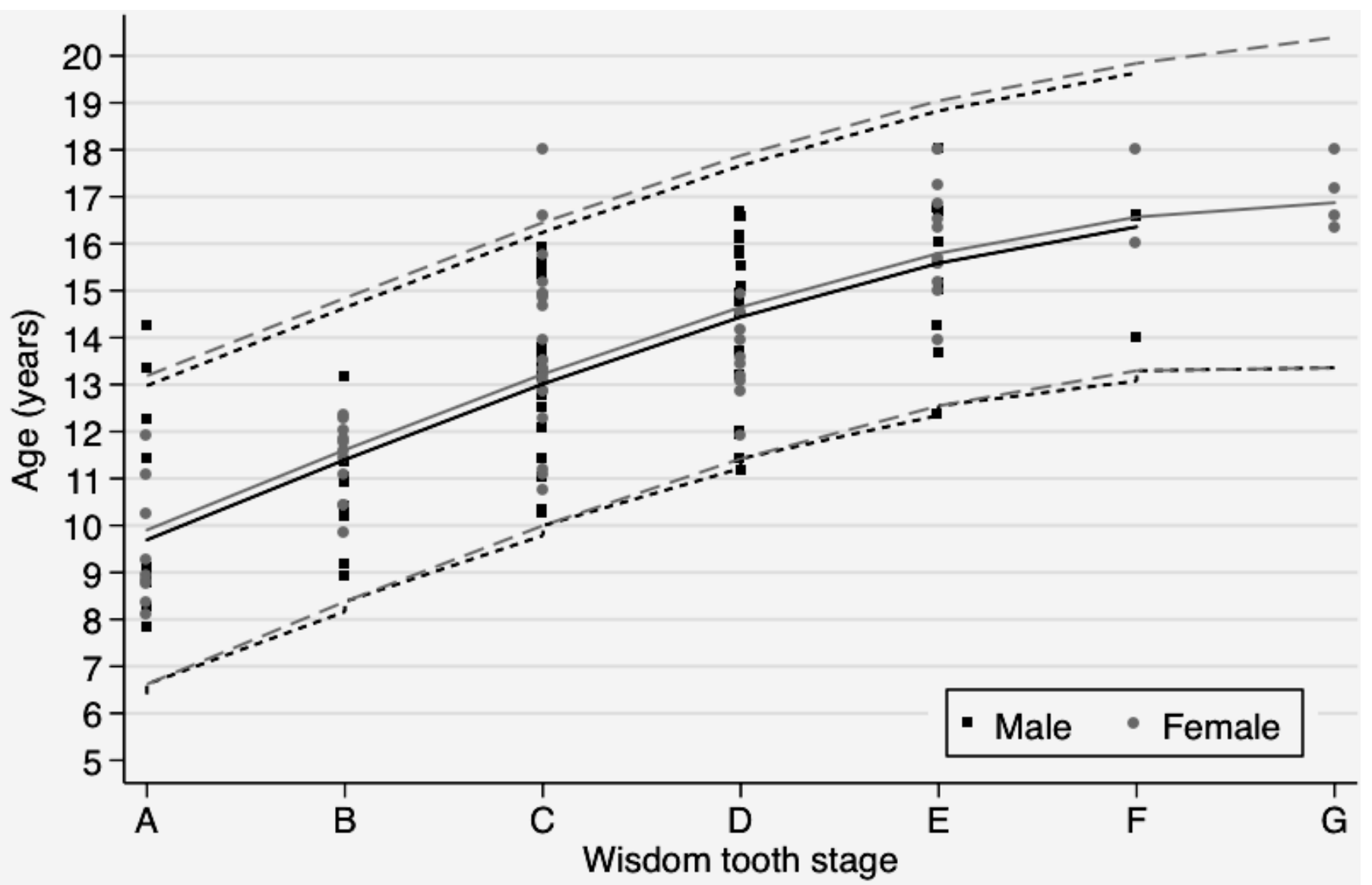

Fig. 2. Prediction of chronological age from mandibular third molar stage

that recognition of earlier stages (A-D) in an individual indicate that person is $<20$ years old. While the presence of stage $\mathrm{F}$ indicates it is highly likely the individual is over 14, and if stage $\mathrm{H}$ has been reached then it is almost certain that the person is $>16$ (Arany et al., 2004).

Prieto et al. (2005) used Demirjian's stages to investigate the relationship between chronological age and dental age of the third molars in a Spanish population. They used a sample between the ages of 14 and 21 years of age, and as they at no time observed a stage lower than $C$, it may be assumed that observation of stage A or B would indicate an individual is $<14$ years in this population. They also investigated the probability of an individual being $>$ or $<18$ years based on third molar development. Stage D-E indicated a high probability a person was $<18$, stage $\mathrm{F}$ indicated it is likely the individual is $<18$, stage $G$ was about 50/50, and stage $\mathrm{H}$ indicated a high probability the individual was $\leq 18$ (Prieto et al., 2005).

Orhan et al. (2007) used Demirjian's classifications to determine the relationship between developmental stages of third molars and chronologic age in a Turkish population sample for the purpose of age estimation. The relationship between third molar development and sex, age and location was also investigated. They found no statistically significant difference between left and right third molars but they did find that maxillary third molar development was commonly more advanced than mandibular third molar development, which is consistent with the findings from Gunst et al. (2003). Males showed advanced third molar development compared to females which is also consistent with other studies (Gunst et al., 2003; Arany et al., 2004; Prieto et al., 2005). In accordance with the above-mentioned study (Prieto et al., 2005) this study found that stage D-E indicated an individual was $<18$, and stage $\mathrm{H}$ indicated an individual was $>18$.

Knell et al. (2009) used only lower wisdom teeth to determine chronological age and found there was an $85 \%$ agreement on stages between left and right sides of the jaw. Of the $15 \%$ that were not the same on both sides of the jaw, the majority differed only by one stage. However, it was found that stage $\mathrm{H}$ was attained at ages less than 18 in some cases, so the above statement that attainment of stage $\mathrm{H}$ indicates the individual is over 18 may not hold true for all situations in all populations.

Third molar development has also been used to estimate chronological age in a Portuguese population (Caldas et al., 2010). In this study the probability of an individual being at least 16 years was investigated. It 


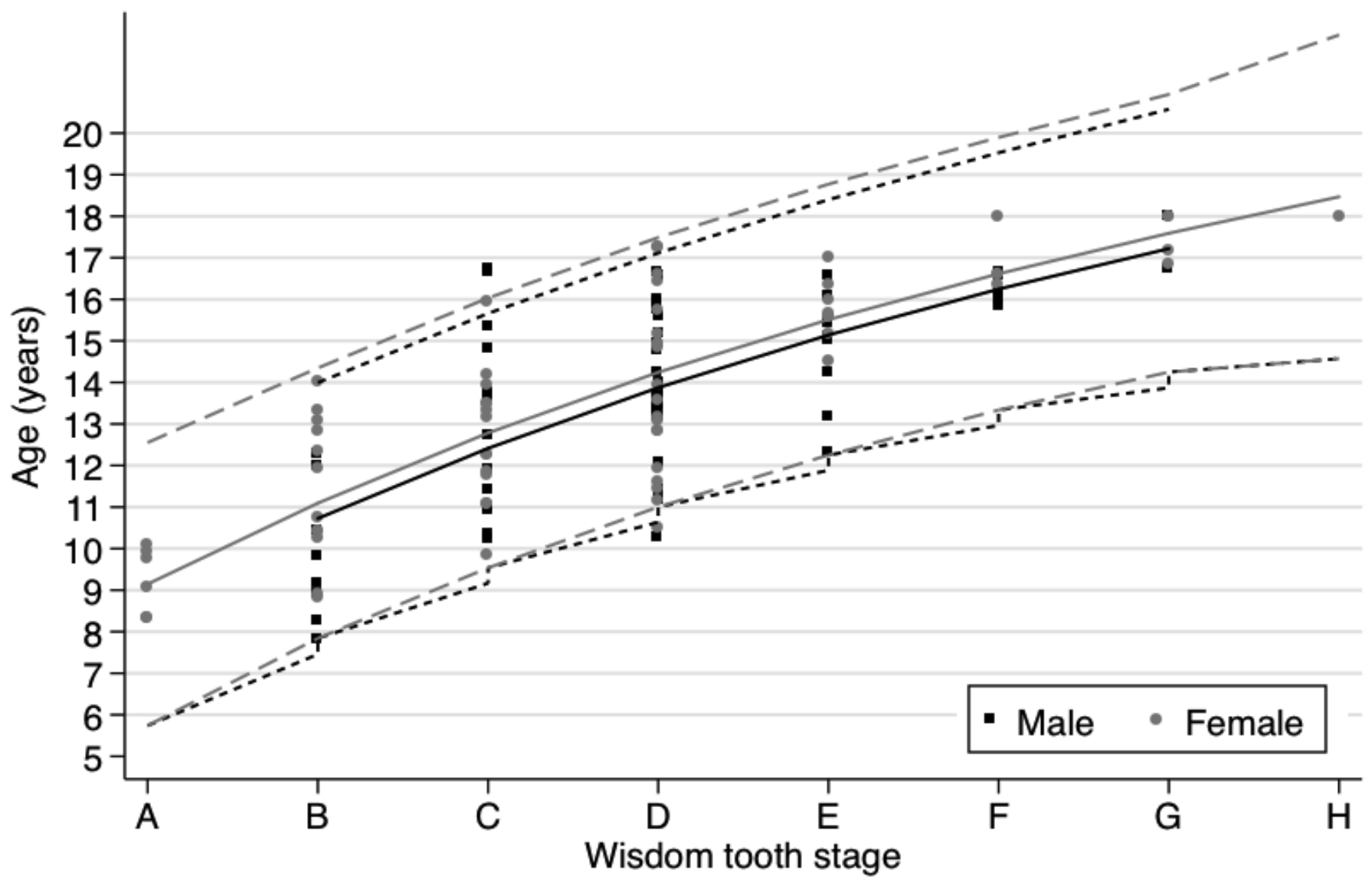

Fig. 3. Prediction of chronological age from maxillary third molar stage.

was found that while sexual dimorphism was not always present for every stage of third molar development; overall, third molar formation occurred earlier in boys, which is in agreement with Gunst et al. (2003). It was suggested that presence of stage $\mathrm{D}$ was perhaps the earliest indicator of an individual being over 16 years of age.

As has been discussed already, after the age of around 14 it becomes increasingly more difficult to determine age as there are fewer teeth undergoing development. There is some controversy in the literature about whether we should be using third molars for age estimation in this age group or whether we should be using skeletal development of the hands and wrists (Demisch and Wartmann, 1956; Engström et al., 1983). A linear relationship between chronological age, skeletal development and third molar formation has been observed (Demisch and Wartmann, 1956). While the correlation between chronological age and third molar development and the correlation between chronological age and skeletal development are comparable (Engström et al., 1983); third molars have the advantage of developing for longer and may be the only developmental marker available in late adolesence
(Mesotten et al., 2002).

It appears that the New Zealand population does not differ significantly in third molar development compared with other populations, as similar trends were found in this study as in other studies on different populations. A slight sexual dimorphism was found with males tending to develop earlier than females, probably because of post-pubertal development of this tooth. This trend was also documented in previous studies (Gunst et al., 2003; Caldas et al., 2010; Orhan et al., 2007; Arany et al., 2004; Prieto et al., 2005; Harris, 2007; Sisman et al., 2007). Additionally, Gunst et al. (2003) reported earlier development in maxillary, compared to mandibular third molars, which is mirrored in the present study. It has been quoted in the literature that the presence of stage $\mathrm{F}$ is indicative of an individual being over the age of 14 (Arany et al., 2004). This trend can also be observed in our New Zealand sample. However, in our sample some individuals who were 18 presented with stage $\mathrm{E}$ or lower, which was not found in some other literature (Prieto et al., 2005). Attainment of stage $\mathrm{H}$ indicating an individual is over the age of 18 was found in the present study and in others (Prieto et al., 2005; Orhan et al., 2007; Knell et al., 


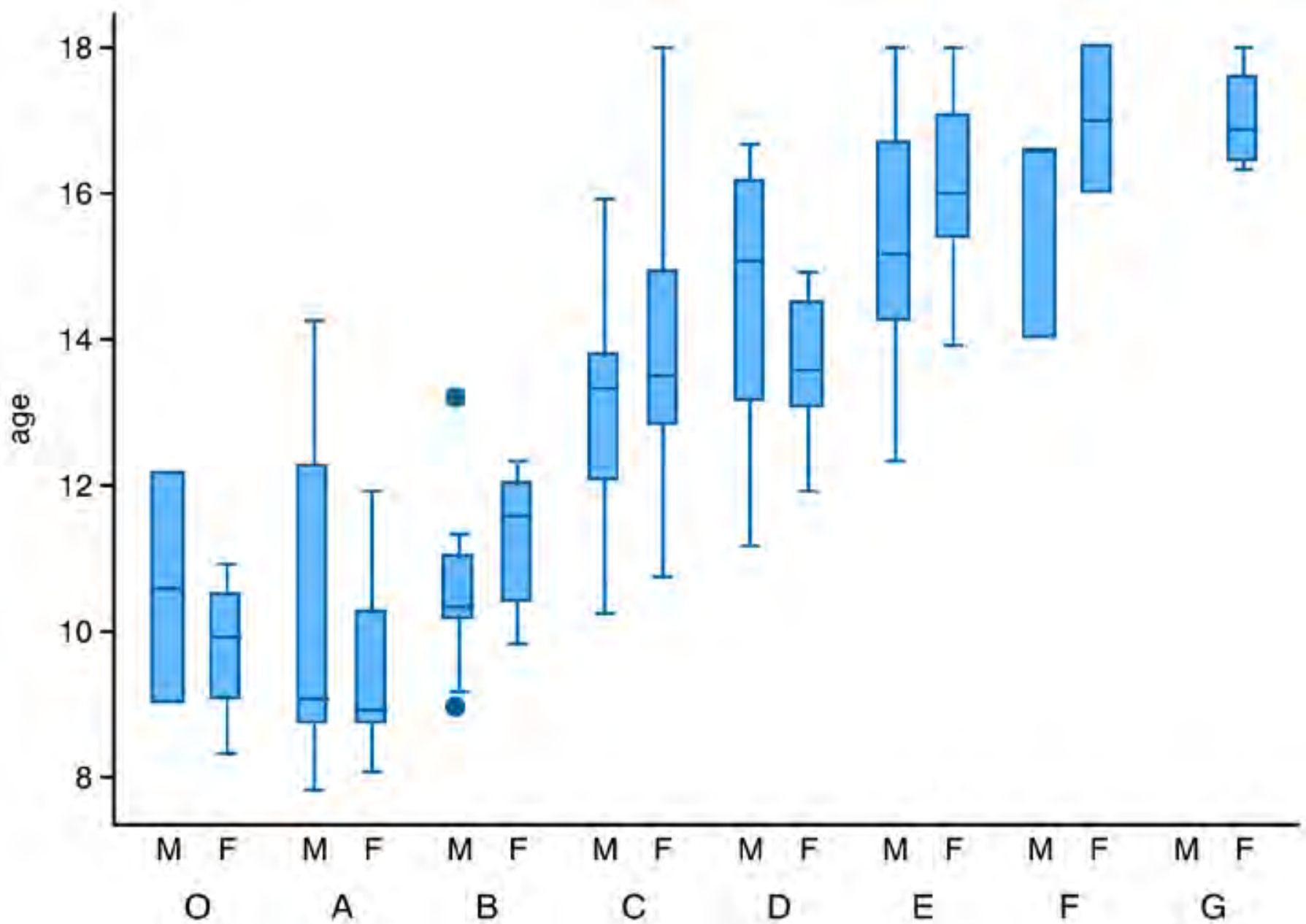

Fig. 4. Prediction of chronological age from mandibular third molar stage

2009).

The principal aim of our study was to evaluate the usefulness of the Demirjian method when applied to third molar development in a sample of New Zealand children. Although we have previously studied dental maturation and cervical vertebral development in three different ethnic groups from New Zealand (European, Maori and Pacific Island, TeMoananui et al., 2008a,b), the present investigation focused on an older age group and made no attempt at recording ancestry. Our focus was on adolescence, a time of major hormonal, growth and secondary sexual changes (Bogin, 2001), rather than on ethnicity. We conclude that while chronological age can indeed be estimated from third molar development, the age range can be relatively broad for given developmental stages.

\section{LITERATURE CITED}

Arany S, Iino M, Yoshioka N. 2004. Radiographic survey of third molar development in relation to chronological age among Japanese juveniles. J Forensic Sci 49:1-5.

Bogin B. 2001. The growth of humanity. New York: Wiley Liss.

Caldas IM, Julio P, Simoes RJ, Matos E, Afonso A, Magalhaes T. 2010. Chronological age estimation based on third molar development in a Portugese population. Int J Legal Med 125:235-243.

Cameriere R, Ferrante L, Cingolani M. 2006. Age estimation in children by measurement of open apices in teeth. Int J Legal Med 120: 49-52.

Demirjian A, Buschang PH, Tanguay R, Kingnorth Patterson D. 1985. Interrelationships among measures of somatic, skeletal, dental, and sexual maturity. Am J Orthodont 88:433-438.

Demirjian A, Goldstein H. 1976. New systems for dental maturity based on seven and four teeth. Ann Hum Biol 3:411-427.

Demirjian A, Goldstein H, Tanner JM. 1973. A new system of dental age assessment. Hum Biol 45:211-227.

Demirjian A, Levesque GY. 1980. Sexual differences in dental development and prediction of emergence. J 


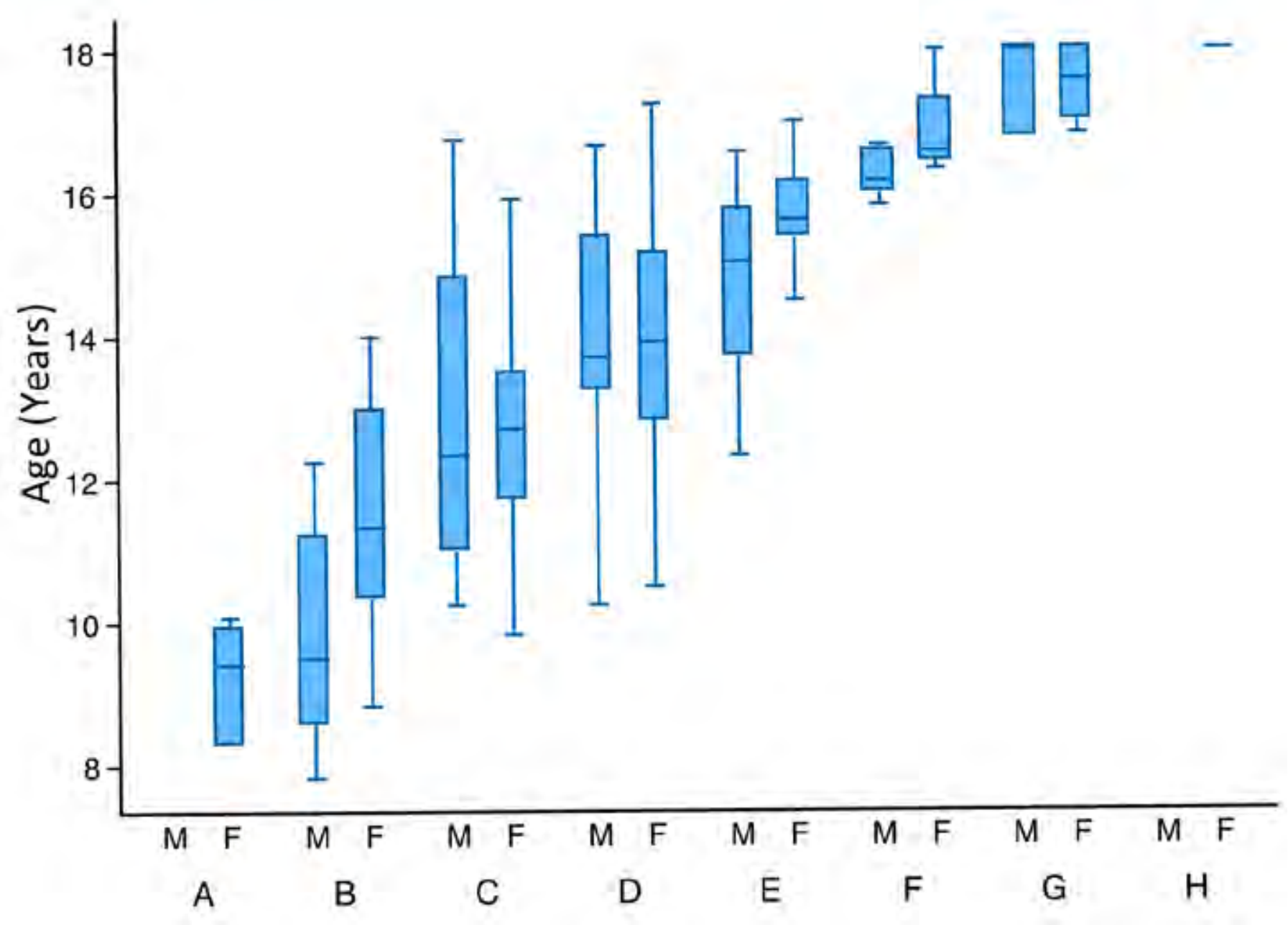

Fig. 5. Prediction of chronological age from maxillary third molar stage

Dent Res 59:1110-1122.

Demisch A, Wartmann P. 1956. Calcification of the mandibular third molar and its relation to skeletal and chronological age in children. Child Dev 27:459-473.

Engström C, Engström H, Sagne S. 1983. Lower third molar development in relation to skeletal maturity and chronological age. Angle Orthod 53: 97-106.

Gunst K, Mesotten K, Carbonez A, Willems G. 2003. Third molar root development in relation to chronological age: a large sample sized retrospective study. Forensic Sci Int 136:52-57.

Hägg U, Matsson L. 1985. Dental maturity as an indicator of chronological age: the accuracy and precision of three methods. Eur J Orthodont 7:25-34.

Harris EF. 2007. Mineralization of the mandibular third molar: a study of American blacks and whites. Am J Phys Anthropol 132:98-109.

Kieser JA, DeFeijter J, TeMoananui R. 2008. Automated dental aging for child victims of disasters. Am J Disaster Med 3:109-112
Knell B, Ruhstaller P, Prieels F, Schmeling A. 2009. Dental age diagnostics by means of radiographical evaluation of the growth stages of lower wisdom teeth. Int J Legal Med 129:465-469.

Kullman L. 1995. Accuracy of two dental and one skeletal age estimation method in Swedish adolescents. Forensic Sci Int 75:225-236.

Lewis AB, Garn SM. 1959. The relationship between tooth formation and other maturational factors. Angle Orthod 30:70-77.

Liversidge HM. 2010. Demirjian stage tooth formation results from a large group of children. Dental Anthropology 23:16-23.

Liversidge HM, Smith BH, Maber M, 2010. Bias and accuracy of age estimation using developing teeth in 946 children. Am J Phys Anthropol 143:545-554.

Mesotten K, Gunst K, Carbonez A, Willems G. 2002. Dental age estimation and third molars: a preliminary study. Forensic Sci Int 129:110-115

Moorrees CFA, Kent RL. 1978. A step function model 
using tooth counts to assess the developmental timing of the dentition. Ann Hum Biol 5:55-68.

Moorrees CFA, Fanning E, Hunt EE. 1963. Age variation of formation stages for ten permanent teeth. J Dent Res 42:1490-1502.

Olze A, Schmeling A, Taniguchi M, Maeda $\mathrm{H}$, van Niekerk P, Wernecke KD, Geserick G. 2004. Forensic age estimation in living subjects: the ethnic factor in wisdom tooth mineralization. Int J Legal Med 118:170173.

Orhan K, Ozer L, Orhan AI, Dogan S, Paksoy CS. 2007. Radiographic evaluation of third molar development in relation to chronological age among Turkish children and youth. Forensic Sci Int 165:46-51.

Prieto JL, Barberia E, Ortega R, Magana C. 2005. Evaluation of chronological age based on third molar development in the Spanish population. Int J Legal Med 119:349-354.

Ritz-Timme S, Cattaneo C, Collins MJ, Waite ER, Schutz HW, Kaatsch HJ, Borrman HIM. 2000. Age estimation: the state of the art in relation to the specific demands of forensic practise. Int J Legal Med 113:129-136.

Saunders S, DeVito C, Herring A, Southern R, Hoppa R. 1993. Accuracy tests of tooth formation age estimations for human skeletal remains. Am J Phys Anthropol 92:173-188.
Staaf V, Mornstad H, Welander U. 1991. Age estimation based on tooth development: a test of reliability and validity. Scand J Dent Res 99:281-286.

Sisman Y, Uysal T, Yagmur F, Ramoglu SI, 2007. Thirdmolar development in relation to chronologic age in Turkish children and young adults. Angle Orthod 77:1040-1045.

TeMoananui R, Kieser JA, Herbison GP, Liversidge HM. 2008a. Estimating age in Maori, Pacific Island and European children from New Zealand. J Forensic Sci 53:401-404.

TeMoananui R, Kieser JA, Herbison GP, Liversidge HM. 2008b. Advanced dental maturation in New Zealand Maori and Pacific Island children. Am J Hum Biol 20:43-50.

Timmins K, Herbison P, Farella M, Liversidge H, Kieser JA. 2011 The usefulness of dental and cervical maturation stages in New Zealand children for disaster victim identification. For Sci Med Pathol (in press).

Willems G, Van Olmen A, Spiessens B, Carels C. 2001. Dental age estimation in Belgian children: Demirjians technique revisited. J Forensic Sci 46:893-895. 